\title{
Yttrium Y 90 Glass Microspheres
}

National Cancer Institute

\section{Source}

National Cancer Institute. Yttrium Y 90 Glass Microspheres. NCI Thesaurus. Code C38679.

An injectable formulation of yttrium Y 90 consisting of glass microspheres containing the radioisotope yttrium $Y 90$. When injected into the tumor vascular bed, yttrium $Y 90$ glass microspheres occlude tumor blood vessels and deliver a cytotoxic dose of beta radiation to the tumor site, thereby reducing the tumor burden. ( $\mathrm{NCl04)}$ 